\title{
RAPID 3D DIGITALIZATION OF THE CULTURAL HERITAGE: A CASE STUDY ON ISTANBUL SULEYMANIYE SOCIAL COMPLEX (KULLIYE)
}

\author{
T. Kan, G. Buyuksalih, G.Enc Ozkan, P.Baskaraca \\ Bogazici Insaat Musavirlik A.S., Evliya Celebi Mah. Mesrutiyet Cad. Eski TUYAP Binasi No. 50 Beyoglu, Istanbul, Turkey - \\ (Tuna.Kan, Gurcan.Buyuksalih, Gozde.Enc, Peyami.Baskaraca)@bimtas.istanbul
}

\begin{abstract}
KEY WORDS: Cultural Heritage, Suleymaniye Mosque and Social Complex, Terrestrial Laser Scanning, 3D Solid Modelling, 360
\end{abstract} Panoramic Images, Virtual Reality (VR)

\begin{abstract}
:
Determination and documentation are the basis of all studies in the context of conservation and sustainability of cultural heritage. Considering the number of historical and cultural properties and their deterioration status, the fastest and most accurate method of documentation is required to be used in these studies. With the development of technology, traditional documentation methods have been replaced by digitization which enables the acceleration of the whole process. 3D laser scanning technology is the most rapid, accurate (metric) and reliable method used in digitization studies of cultural properties / cultural heritage nowadays. By using laser point cloud data, 3D model of cultural properties can also be generated quickly and in detail as well as documentation and digital archiving. At this point, the integration of digital camera or $360^{\circ}$ panoramic camera, which is very popular today, and point cloud data makes a significant contribution to further analyzes. This study expresses the 3D digitalization processes of the Suleymaniye Külliye (Mosque and Complex), which is included in the UNESCO World Heritage List. 3D model and VR applications, which are also outputs of the study, are discussed at the end part.
\end{abstract}

\section{INTRODUCTION}

Cultural heritage is the symbol and proof of the existence, identity and sustainability of human beings, societies and the cultural groups that originate the society. It is a social responsibility to protection/conservation/presentation this cultural heritage and transmission to future generations. The first stage of the process in the conservation of architectural heritage is documentation; which is registering the current status of historical and cultural properties through various measurement methods (traditional manual measurement, photogrammetric measurement, terrestrial laser scanning) by transforming them to inscriptions, drawings and photographs. Rapid and accurate documentation is becoming vital nowadays as cultural properties are by being ruined and destroyed by some environmental factors (natural disasters, vandalism, dysfunction, material aging, etc.). With the development of technology, traditional documentation methods have been replaced by digitization which enables the acceleration of the whole process; so transmission of to future generation has become more secured.

Methods and approaches for sustainable conservation of cultural properties has becoming more important these days (Ulusoy Binan, 2018). In this context, due to fast and accurate documentation, it will be possible to provide fast analysis, reactive monitoring and rapid intervention opportunities with the periodic documentation of studies over time.

3D data acquisition methods such as airborne, mobile and terrestrial laser scanning systems can be applied on the documentation of cultural heritage. In the context of architectural detail, terrestrial laser scanning technology is the fastest and most reliable method. The use of digital methods in data acquisition also facilitated the digital model of the structure to be moved to the office environment.
For the sustainable conservation of cultural property, it is necessary to define the asset, to reveal outstanding universal value and to promote the site (Kan, 2014). Virtual visit, promotion and creation of $3 \mathrm{D}$ solid model that reflects the material and texture of the site as well as the 3D point cloud data itself, are the products that can contribute in the context of conservation.

Istanbul is a major city where many cultures have been settled for centuries due to its strategic location. Therefore, it has been home to cultural properties belonging to different periods from ancient times. The UNESCO World Heritage Committee defines the term World Heritage as "our heritage from the past, what we have experienced today, and what we have passed on to future generations". It indicates that our cultural and natural heritage is an irreplaceable source of life and inspiration. Within this scope, Istanbul is a UNESCO World Heritage Site since 1985 with its Historical Areas (Suleymaniye, Sultanahmet, Zeyrek, City Walls). Suleymaniye Complex and its surroundings together with other historical sites in the Historic Peninsula, has been listed by the UNESCO World Heritage Committee under the criteria of (i) $)^{1}$, (ii) ${ }^{2}$ and (iv) ${ }^{3}$ (UNESCO, 2017, URL01).

In this study, 3D digitalization studies, processes and methods of Suleymaniye Complex are discussed, especially the process steps of acquisition of laser scanning and $3 \mathrm{D}$ point cloud data

\footnotetext{
${ }^{1}$ (i) to represent a masterpiece of human creative genius;

2 (ii) to exhibit an important interchange of human values, over a span of time or within a cultural area of the world, on developments in architecture or technology, monumental arts, town-planning or landscape design;

${ }^{3}$ (iv) to be an outstanding example of a type of building, architectural or technological ensemble or landscape which illustrates (a) significant stage(s) in human history;
} 
are explained in detail. In conclusion, the 3D model of Suleymaniye Complex and the virtual reality (VR) of this model are introduced. The HTC Vive goggles and its navigation stages and results in the VR environment are presented. In addition, shots taken by $360^{\circ}$ panoramic cameras and the effects of overall panorama to the conservation process are also examined.

\section{THE SULEYMANIYE MOSQUE AND SOCIAL COMPLEX IN ISTANBUL, TURKEY}

Kulliye's are building complex with multiple functions built at the same time. Suleymaniye Kulliye is the most important Ottoman period building after communities the Fatih Complex in Istanbul.

Suleymaniye Kulliye is the most comprehensive building complex in Ottoman period after Fatih Kulliye in Istanbul. As being a monument of Architect Sinan and a representative of classical Ottoman architecture, it was accepted as a "World Heritage Site" with its traditional residential texture. The Suleymaniye Complex is defined as the 'masterpiece of Sinan architecture' and 'the best example of religious architecture' in the 'World Heritage Site' document of the ICOMOS official record dated 31 December 1984. With its architectural design and ornaments (hand-carved, stained-glass, wood ornament, glazed tile, etc.), interior architecture elements (mihrab, mimbar, mahfils, etc.), cultural landscape value and spiritual values (religious structure); Suleymaniye Complex has outstanding universal value and significance (Kan, 2014).

Suleymaniye Complex, which was built by Kanuni Sultan Suleyman (known in the Western world as Suleiman the Magnificent) in the mid-16th century (1550-1557) by Architect Sinan, is located on a slope overlooking the Golden Horn to the north of the Historical Peninsula. Figure 1 illustrates the region including the Complex and Suleymaniye World Heritage Site.

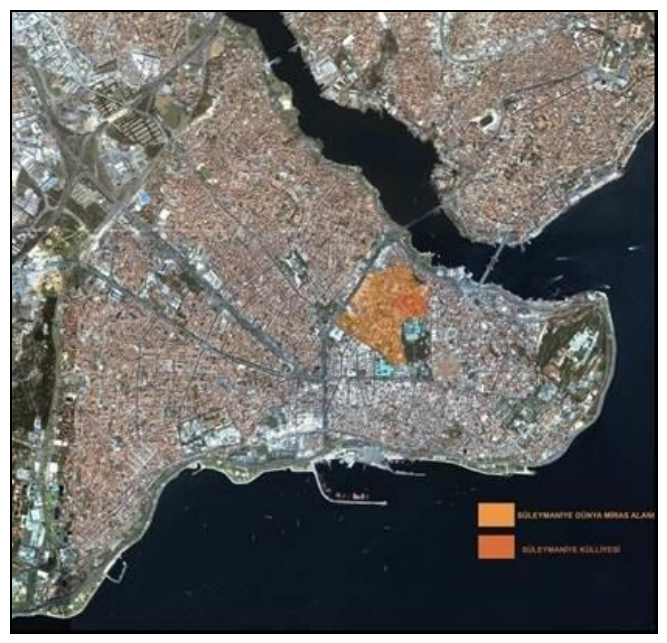

Figure 1. Suleymaniye World Heritage Site and Complex

The mosque is located in the center of the Complex and framed by the other structures. The mosque, which is the most dominant structure of the complex and its cloister, are located in a large garden. There are 10 doors to the outer courtyard. The "hazire" (a special Ottoman cemetery) and the tombs of Suleyman and Hurrem Sultan are located in this area The mosque is separated from the other Complex buildings along the garden walls with the streets passing. The other buildings of the Complex have the function of filling or unloading of the ground to consist the platform where the mosque sits.

The cloister is in the northwest direction of the mosque and is covered with white marbles and has a pool in the middle. Evvel and Sani Madrasah, Primary School and Medical Madrasah are located in the South; the Daru's-sifa (hospital), Imaret (soup kitchen) and Tabhane (guesthouse) are located in the West and Salis and Rabi Madrasah and Mulazim Madrasah are settled in the north. Darul-hadis Madrasah, located in parallel to the north-eastern direction, forms a small courtyard between the wall of the mosque and the wall of Istanbul University (Old Palace). The madrasahs (Salis and Rabi) to the north of the mosque are located in accordance with the slope. Mulazim Madrasah $^{4}$ are located by taking advantage of the elevation difference in the northern part of the madrasahs.

The rows of shops are located under the northern garden wall of the mosque are the Bakircilar Bazaar. This façade is completed by the section of Mimar Sinan tomb and house which is located westward in this direction. North of the mosque, from the North to the South, 'Tabhane', 'Imaret' and 'Daru's-sifa' is located. Caravansary and barn sections are located in the lower part of the buildings by parlaying the elevation difference between the facades of the mosque and the rear facades. The shops of Tiryakiler Bazaar, which are facing the western facade of the mosque, constitute the ground floor of the Evvel, Sani and Medical Madrasahs located in this section. The complex structures and their names are given in Figure 2.

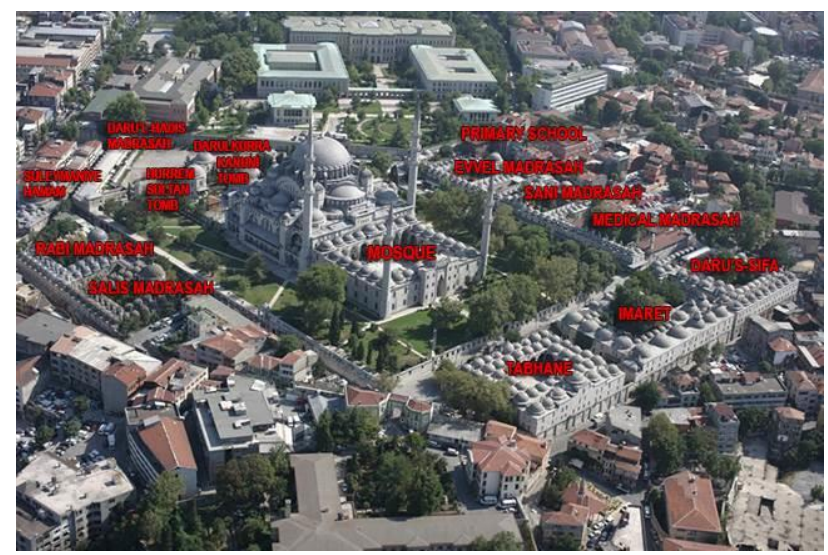

Figure 2. Structures of the Suleymaniye Complex

The main dome of the mosque, which has one full and two halfdomes, and built on four columns, is 26.50 meters in diameter while 53 meters in height. As being a reflection of the Classical Period Ottoman architecture, Suleymaniye Mosque which has a simple formation determined by structure system in architecture, stands out with its design fineness in its architectural details. Beside the doors and windows of the mosque in the classical period, structural elements such as mihrab (a semicircular niche in the wall of a mosque that indicates the qibla), minbar (a pulpit in the mosque where the imam stands to deliver sermons) and mahfil (a special raised platform in a mosque where muezzin kneels and chants in response to imam's prayers) reflect a fine aesthetic approach. The design of the minbar by Mimar Sinan is the product of an excellent marble workmanship.

\footnotetext{
${ }^{4}$ Mulazims who completed their education in the madrasa would stay in here until they found a job.
} 
The monument, which was built as a symbol of emperorship of Sultan Suleiman the Magnificent, has materials from different places as a reflection of the borders of the empire at that time. The architecture of the mosque, which is the main element of the complex, and its materials are symbolizing the design of the great empire.

The arches carrying the wall in the large side arches are seated in four porphyry columns. It is understood from Sinan's life story and construction notebooks that one of these four columns was brought from Alexandria and the other from Ba'albek, the third from the Fatih Mosque and the fourth from the garden of Topkapı Palace (Kan, 2014).

In this study, a mosque in the centre of Suleymaniye Complex, which is located in a large garden, and other surrounding structures were measured. Figure 3 shows a picture from the internal part of the mosque. It was not possible to enter into all units of the complex which is in use of different institutions nowadays. The mosque part, which is also a touristic point of interest, is open to worship. Therefore, the studies were carried out when there was no worship and tourist density was decreased. At this stage of the study, the mosque was scanned with its interior and exterior spaces, while the outer elements of the complex's exterior space were scanned. Figure 4 includes a plan showing the scanned part of the Complex (indoor and outdoor).

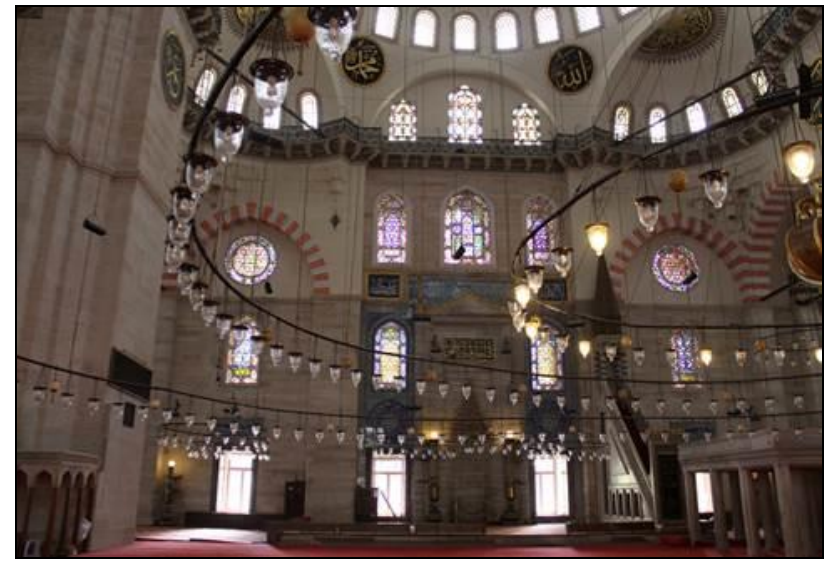

Figure 3. Indoor image from the Mosque

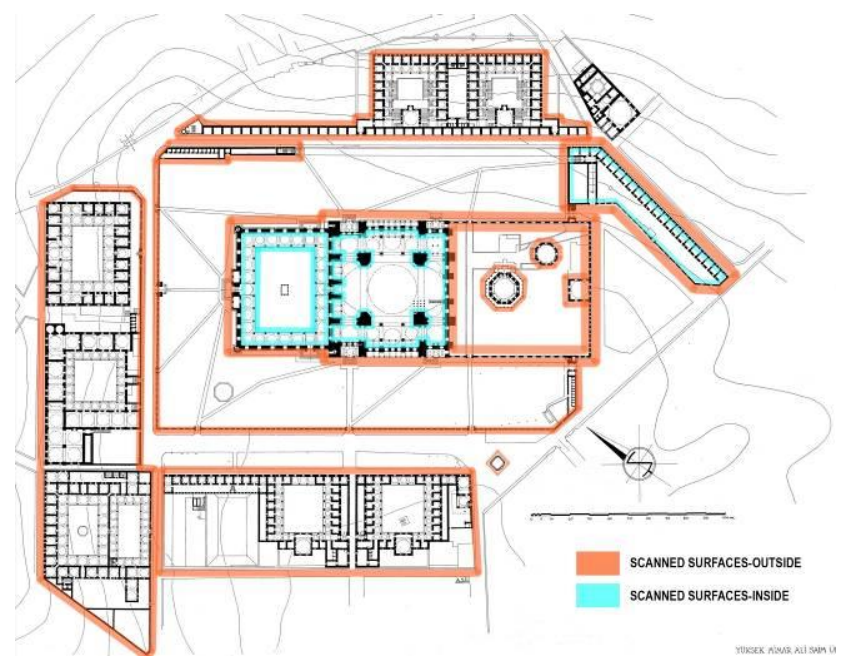

Figure 4. Scanning part of the Complex buildings in plan view

\section{WORKFLOW}

The following workflow (see Fig.5) has been carried out to generate a detailed virtual 3D model of Suleymaniye Complex: (1) data acquisition using terrestrial laser scanning with Riegl VZ400 scanner with Nikon D610, (2) Registration and georeferencing of scans using Riscan, (3) segmentation of point clouds in tiles in Riscan, (4) re-organisation of point cloud tiles in ReCap as preparation for modelling in 3ds Max, (5) 3D solid modelling with $3 \mathrm{ds}$ Max using segmented point clouds, (6) texture mapping of polygon models with $3 \mathrm{ds}$ Max, (7) data conversion for the import into the game engine Unity, (8) development of motion control and interactions in Unity, (9) implementation into the HTC Vive, and (10) immersive and interactive visualisation of the Complex in the VR system HTC Vive using Steam VR as an interface between game engine and HTC Vive.

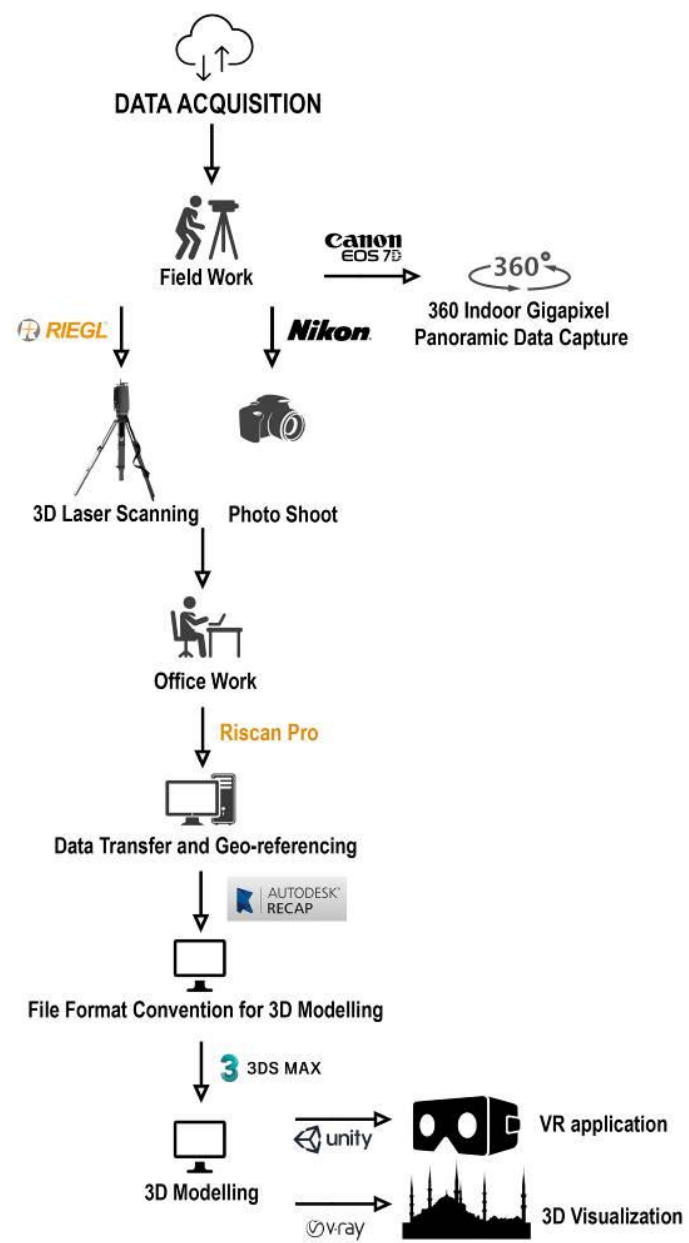

Figure 5. Workflow

\section{DATA ACQUISITION AND 3D MODELLING}

3D laser scanning of the Suleymaniye Complex with an area of 6.8 hectares was carried out in November 2017. Suleymaniye Mosque with its indoor and outdoor parts, and other complex structures with their outdoor parts were scanned by the laser scanning team consisting of 3 persons in approximately 10 days. Data acquisition was completed a total of 730 sessions including 175 sessions are in the mosque, 167 sessions are in 
the courtyard and the exterior, and 388 sessions are in the exterior facades of the other complex buildings and their surroundings.

The Riegl VZ-400 laser scanner was used in 3D scanning (see Fig. 6), and a total station and GPS device were used for georeferencing. The laser scanning device has a repetition rate of up to 500.000 points per second (high speed). The scanning angle is $360^{\circ}$ in horizontal, $100^{\circ}\left(+60^{\circ} /-40^{\circ}\right)$ in the vertical, scanning range is $350 \mathrm{~m}$ in high speed mode, while $600 \mathrm{~m}$ in long range mode, angular resolution is $0.0005^{\circ}$ and scanning accuracy is $5 \mathrm{~mm} / 350 \mathrm{~m}$. 3D scanning and geoferencing studies carried out with a team of five people totally; three were for laser scanning and two were for total station and GPS.

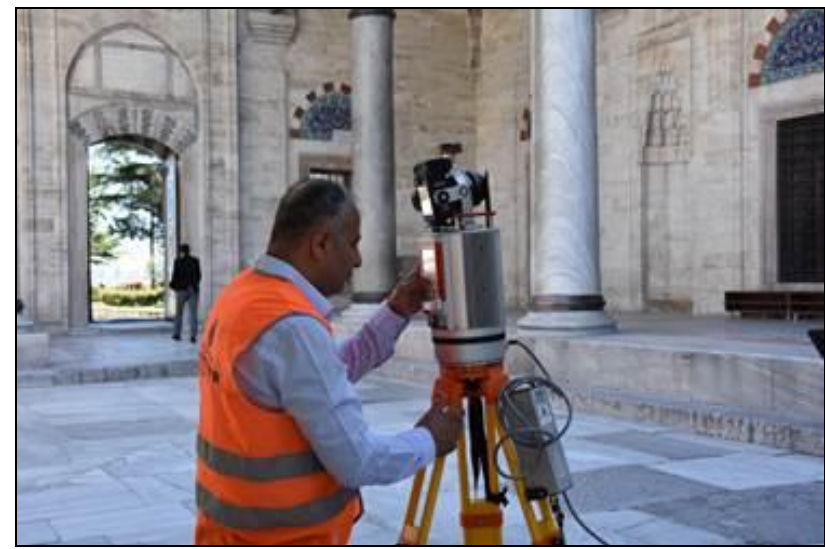

Figure 6. Riegl VZ-400 laser scanner at Suleymaniye Complex

Images taken by the Nikon D610 camera mounted on the laser device were used for colourizing the point cloud from the laser scanning. Five images were taken in each session. All scans which are approximately 2.5 billion points were combined in 2 $\mathrm{mm}$ precision by using multiple adjustment in RiScan Pro software. Whole processes including the data transfer, merging by georeference and cleaning the noisy points ended in 20 days. The point cloud data obtained after the processing step in .rsp format was converted to .pts format in order to be run on 3D modeling software. Figures 7 and 8 show the colorized point cloud of indoor and outdoor parts of Complex respectively.

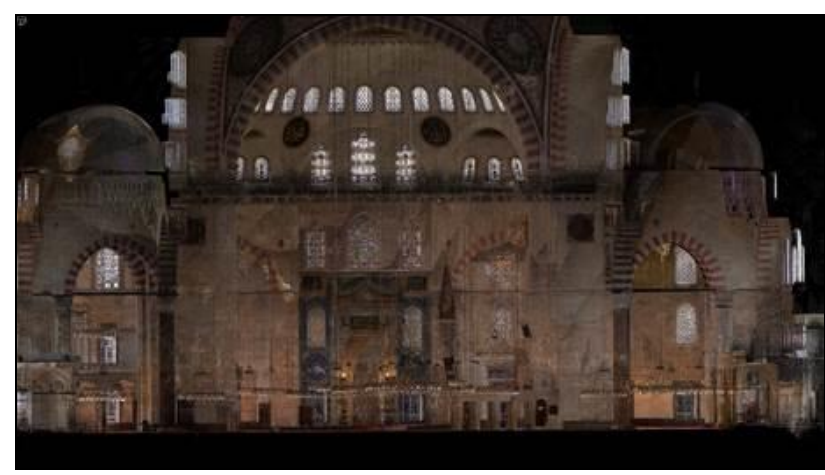

Figure 7. The view of colourized point cloud data in Riscan (interior view of Suleymaniye Mosque)

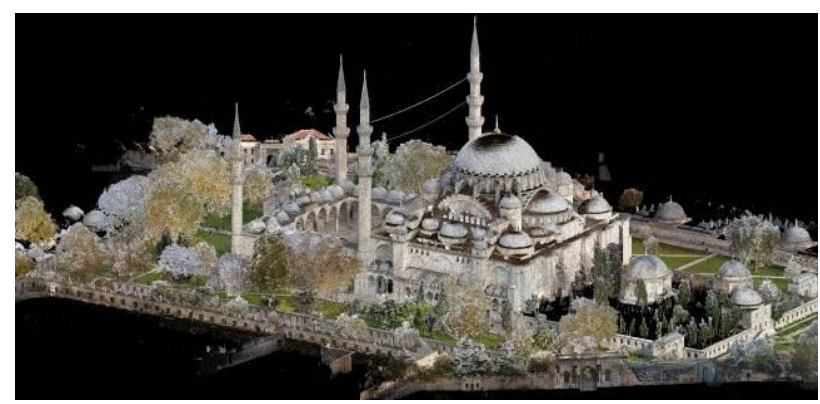

Figure 8. The view of colourized point cloud data in Riscan (Suleymaniye Mosque and complex exterior view)

At this stage, the georeferenced and colorized point cloud data is converted to .rcp and .rsp format in Autodesk Recap software in order to be able to used in modelling softwares. Then, solid model was obtained by polygon knitting method on the surfaces thereby handling the scanning data as a reference in $3 \mathrm{ds}$ Max software. The surface knitting method was used to achieve a number of polygons that could allow the model to be used in different applications. There was no measurement errors and deformations caused by the point cloud in the use of this technique. In this way, 3-dimensional survey has been obtained in metric and geometric precision and the final model can also be exported to 2-dimensional building surveys. Figures 9 and 10 illustrate the examples of $3 \mathrm{D}$ modelling work from laser point cloud.

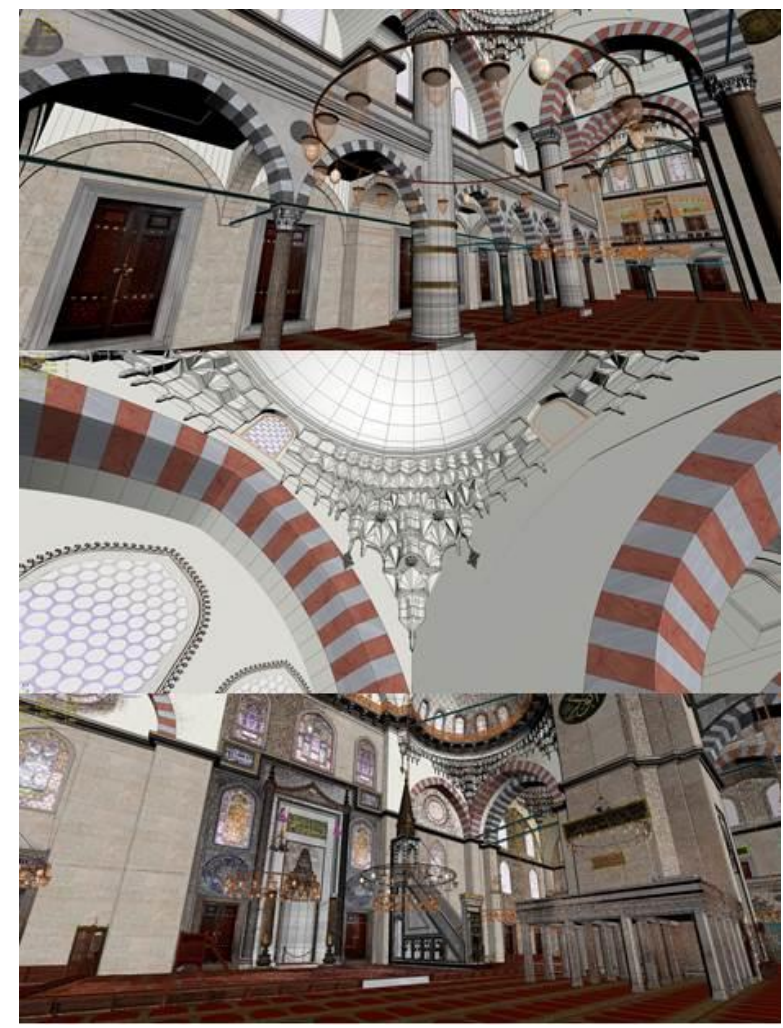

Figure 9. 3D model from point cloud in 3dsmax (interior) 


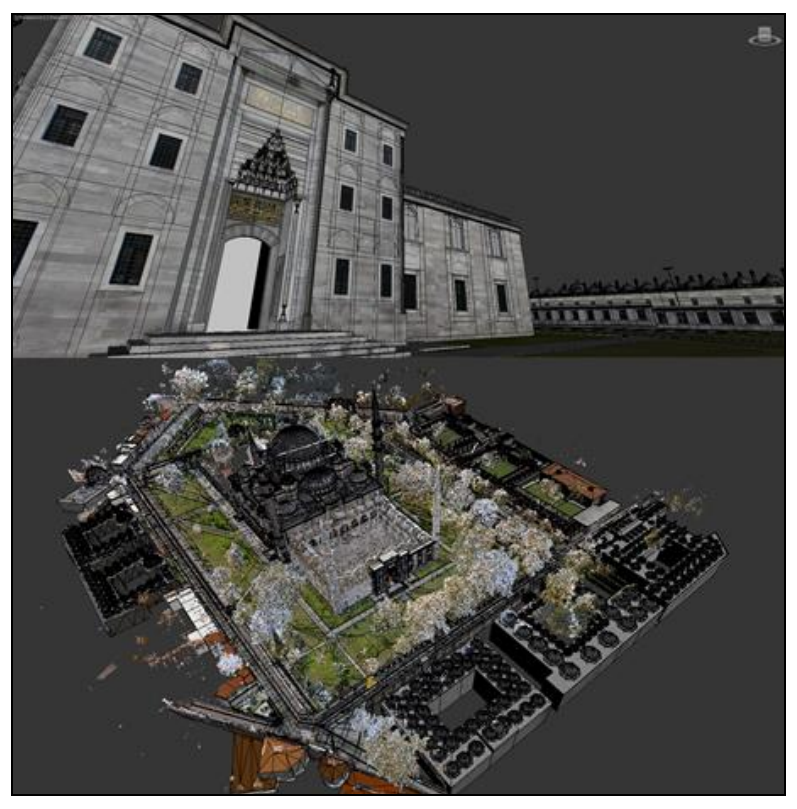

Figure 10. 3D Model from point cloud in 3dsmax (exterior)

Before starting the modelling, images were initially taken in the field to obtain the data to be used for texturing the materials. The team of 2 people completed this study in 15 days with Canon EOS 50D and 18-55 mm lens camera. Different approaches were performed in the interior and exterior parts to express the original colors and texture of the materials. In outdoor photography, shots were taken every time when the light was always at the same angle and intensity. In this context, it was experienced that the most real form of material color and texture was obtained on cloudy days. For indoor shooting, manual and long exposure shots were performed with special lighting from time to time to obtain true texture and color. Totally 4222 images were taken in a resolution of $4752 \times 3168$ pixels. 3124 images of these are detail shots while 1098 are in regular shots. 3596 of these imeges were used in outdoor materials (mosque and other complex structures) while 626 were used in indoor materials (mosque). The reason for this number is the fact that the real details of the cultural properties are used in the place where they are located.

As a method of working at the modeling stage, a program has been carried out in such a way that one person will work the interior of the mosque and one person to work outdoors and other structures. After sorting out of the images, the final product was obtained by proceeding the steps of; creating the pieces of the model from the point cloud, texturizing the metarials and merging respectively in the office environment. Existing polygons have been reduced in order to run the application more effectively and to be able to integrate to the other visualization tools (virtual reality application) with the images (Figure 11). In this context, the number of polygons of the final model is approximately 2.3 million.

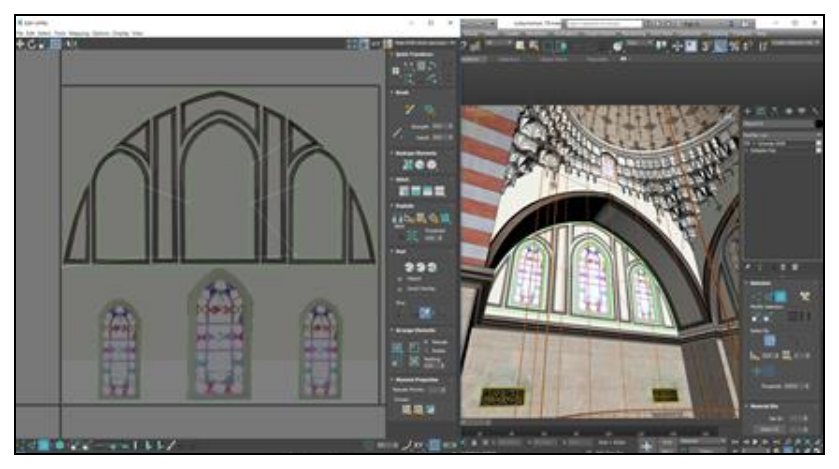

Figure11. Model and material texturing process

Figures 12 (a) and (b) show some printscreens of indoor and outdoor in 3D model. Similar studies were also published by Dursun et.al (2008), Kersten et.al (2009), Kersten et.al (2017), Kan et. al (2017) and Tschirschwitz et.al (2019).

The 3D modeling of interior and exterior parts of Suleymaniye Mosque and exterior sections of the other complex buildings was finalized by 2 people in 7 months. Some printscreens of 3D models from Complex's outdoor and indoor can be seen in Figures 12 (a) and (b) respectively. Similar workflows were already presented by Dursun et.al (2008), Kersten et.al (2009), Kersten et.al (2017), Kan et. al (2017) and Tschirschwitz et.al (2019).

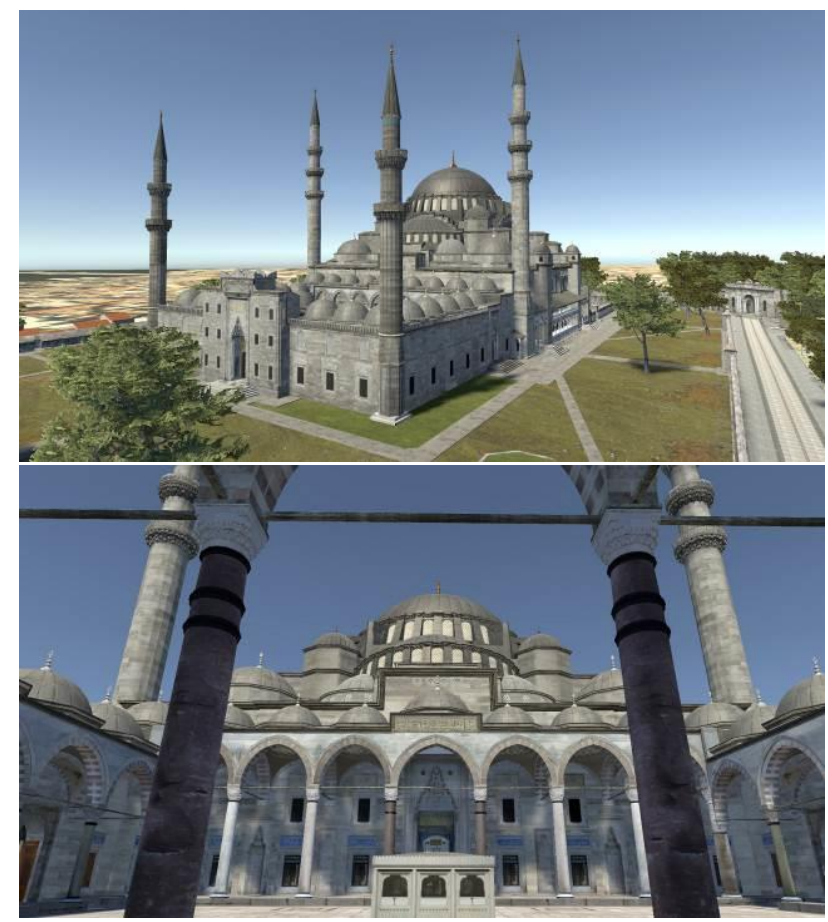

Figure 12 (a). The final 3D model (exterior) 


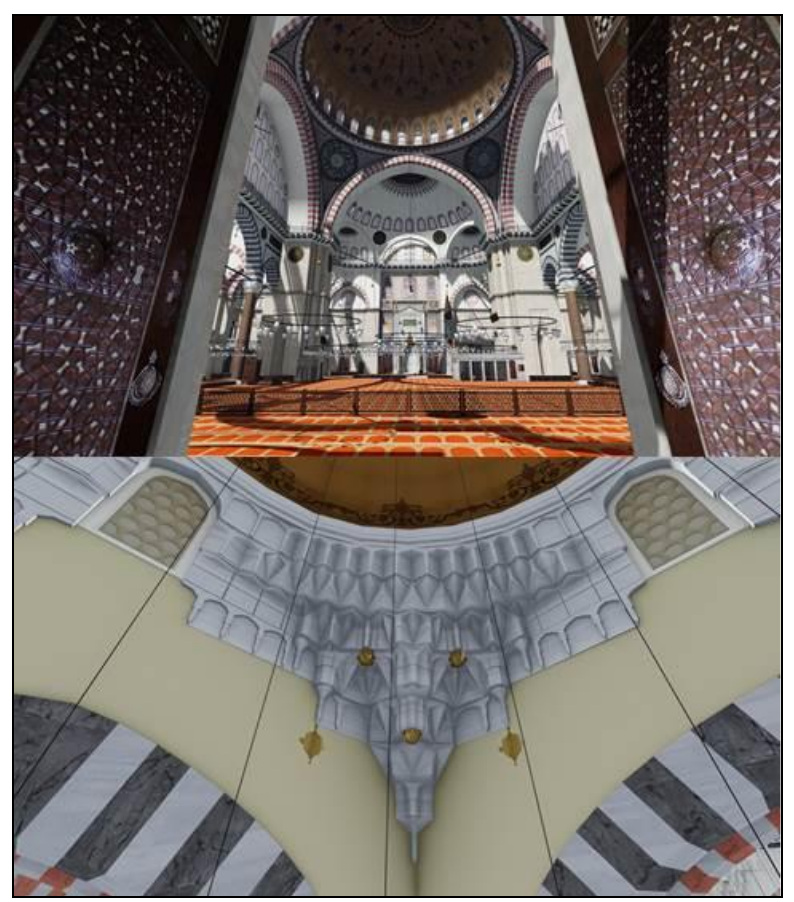

Figure 12(b). The final 3D model (interior)

\section{360 DEGREE PANORAMIC GIGAPIXEL PHOTO CAPTURING}

Suleymaniye Mosque is a master work with its tangible and intangible values as a World Heritage. The mahfil for muezzin (the person appointed at a mosque to lead and recite the call to prayer for every event of prayer and worship in the mosque) and mahfil for sultan, which is in the main place of the mosque, has a fine workmanship, rises above the marble columns and has a brass paths. Besides, ambos (the sermon chair), wreathed fountains located on the two standing columns at the entrance side and the famous stained-glass artist of the period, drunk Ibraham's handworks are seen as other artistic items.

According to the inscriptions in Suleymaniye Mosque, it has been known that the calligraphies on the main dome, half domes, tromp and lion breasts were performed by the famous calligrapher of the period Hasan Karahisar-i. The calligraphies were restored by Abdulfettah Efendi who was another important calligrapher in the $1860 \mathrm{~s}$. These architectural elements, wall decorations and calligraphy, which are the most important elements of the complex in the interior of the mosque are the intangible values of the cultural properties as the greatest representative of the era (Kan, 2014). For this reason, in addition to laser scanning and capturing the images, $360^{\circ}$ gigapixel photography was taken in order to have better documentation and understanding of these values.

The Canon EOS 7D mk II camera, which uses Canon EF 70$200 \mathrm{~mm} \mathrm{f} / 2.8$ lens was used for this capturing. This camera has a 20.2 megapixel CMOS sensor. The size of each images is $5472 \times 3648$ pixels. Panoramic shots are performed automatically with the Roundshot VR and a full 360 degree panorama shot is completed in about 6 seconds. Figure 13 shows $360^{\circ}$ panoramic image acquisition using Canon camera in the mosque.

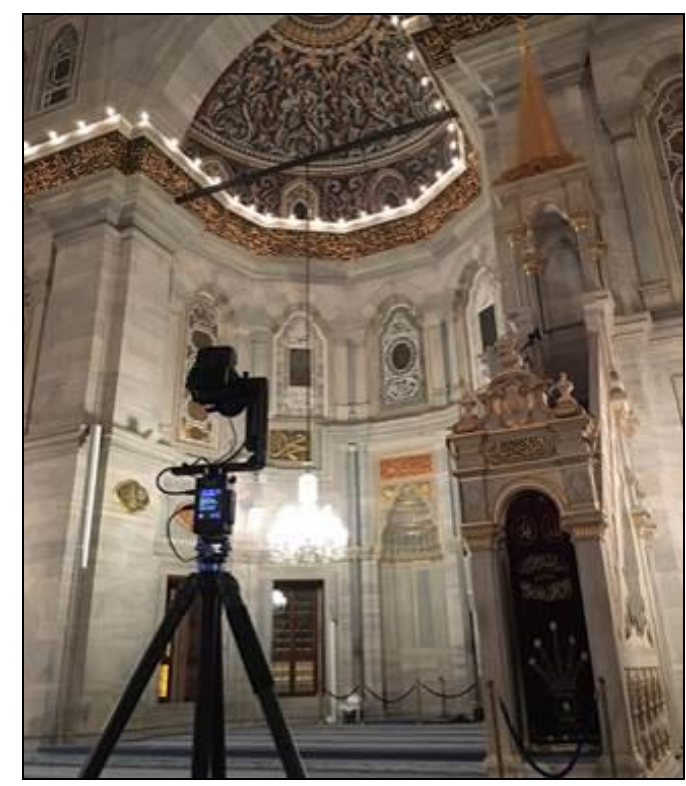

Figure $13.360^{\circ}$ panoramic image acquisition with Canon EOS 7D camera in the Suleymaniye Mosque

Because the mosque is open to public and tourist attractions during the day, the gigapixel capturing campaign was made at night. Some of the general interior lighting armatures were extinguished in order to get a natural image. The tripod was not placed under the main dome due to its effect on the field of depth because of the chandelier located in the middle of the main dome. The appropriate position and leg height were determined by checking the field of depth. For this purpose, the equipment has been established and the appropriate position has been determined by carrying it as a whole. Panoramic shots are practised with full manual adjustment.

The required settings such as lens type, shooting angle and overlap ratio are made via VR drive. $70 \mathrm{~mm}$ lens, 360 degree shooting angle and $30 \%$ overlapping ratio values were used in Suleymaniye indoor gigapixel capturing and finalized in 2.5 hours. In order to prevent problems during the shooting (charging control, dislodge of connection cable, etc.), the wireless apparatus on the VR drive was connected to a mobile phone application and was monitored throughout the operation.

When the capturing of the Mosque was completed, 395 images and an xml data generated by VR drive including roll, pitch and yaw information were obtained. This data was imported to Ptgui software (Fig. 14) together with the panoramic imagery and stitching process was performed. In case of unstitched parts, it was complete with manual control points for pixel matching. Then, it was exported from ptgui with .psb format and imported to photoshop software for image enhancement like color balancing, light corrections etc. As a conclution the overall panorama has about 6 gigapixels resolution. 


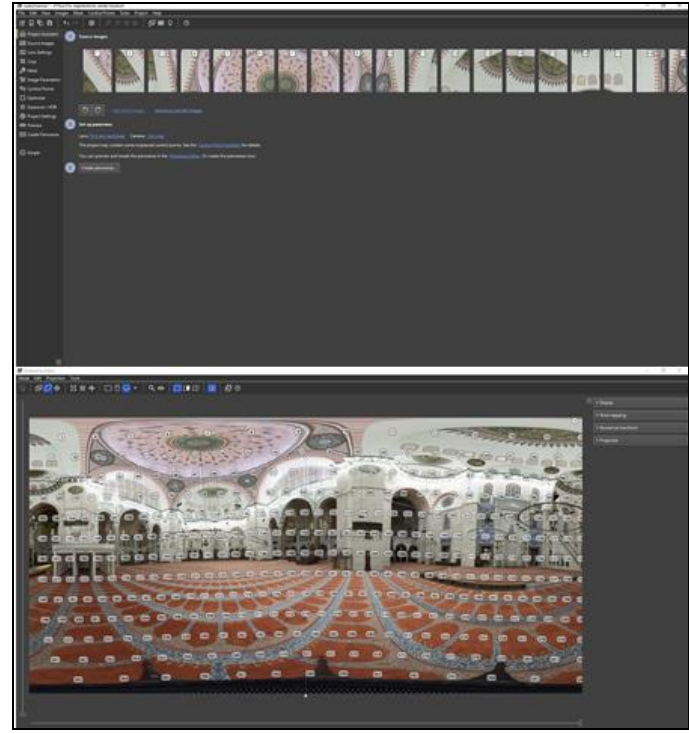

Figure 14. The processing of indoor gigapixel panorama in Ptgui software

After the post-processing steps, it was exported to the Panotour software in .psb format for presenting the data on the web platform. This software was used to divide large size image files into small mosaic pieces so that it can be viewed on the web. The final product from Panotour which has a filing content of mosaic pieces is in a html extension and can be displayed with $3 \mathrm{D}$ glasses or normal mode in 360 degrees on the web.

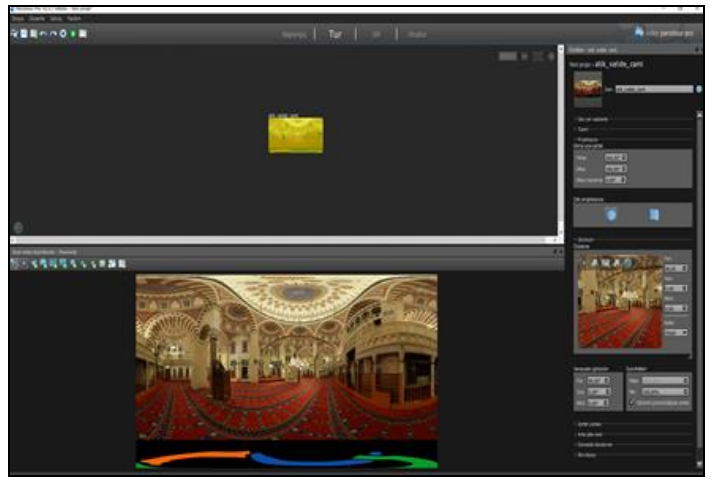

Figure 15. Panotour software preparation for web output

\section{VIRTUAL REALITY (VR) APPLICATION}

Unity3D game engine was used in order to integrate the Suleymaniye Mosque into the virtual reality application. This software is preferred thereby having more common usage, shorter processing time for exporting the model to the virtual reality environment, being more widely used software language and being convenient for the software developments.

Based on the before experiences with the same program, the model generated according to the acceptable number of polygons on the Unity platform was exported in fbx format. The 3D model of the Mosque was transferred to the game engine in .fbx format. Since the models are created with low number of polygons, the performance of virtual reality implementation has been quite high. In the Unity software, various improvements and elaborations (material, light etc.) were accomplished on the model. However, some limitations have been introdured in order not to cause any problems during the trip of the Mosque in the virtual reality environment (permeability of walls and floor, view and height of camera position etc.). After all of these processes, the physical environment was arranged to be able to navigate in the virtual reality environment. HTC Vive headset is used for VR application. HTC Vive (www.vive.com) is a virtual reality headset (Fig. 16) for room-scale virtual reality. Basic components are the headset for the immersive experience, two controllers for user interactions and two "Lighthouse" base stations for tracking the user's movement. After the preparation of the required instruments (VR glasses, hand-sticks and base stations), the boundary was defined in the space to ensure the free movement of the user and the environment was made ready for travel. Fig. 17 shows the Virtual Reality System HTC Vive in action, while a user navigates through the mosque 3D model. Apart from this, Fig. 18 shows the person roaming inside the $360^{\circ}$ panorama image of the mosque as well. This situation provides an excellent opportunity for the user to recognize and compare details in both.

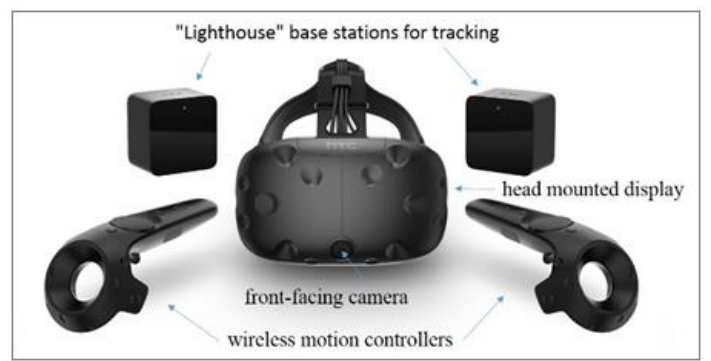

Figure 16. The components of the HTC Vive VR System

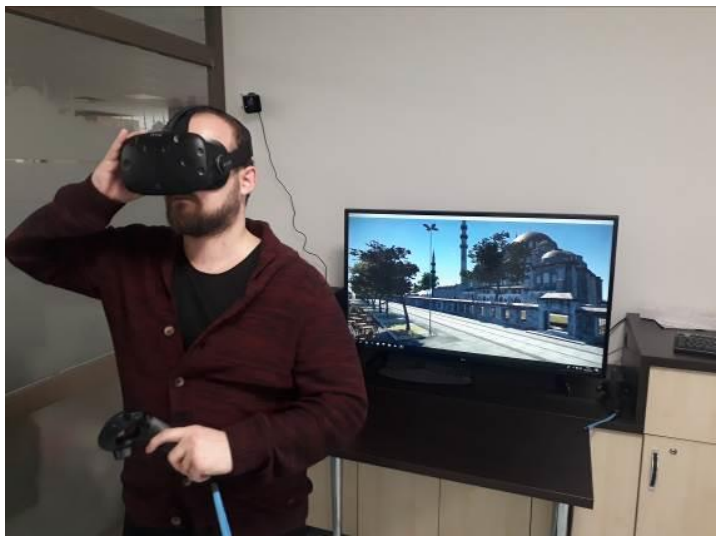

Figure 17. A scene from VR application in the Mosque

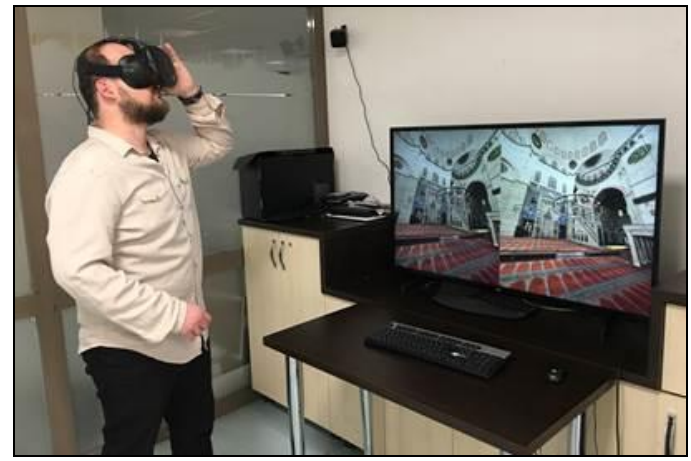

Figure 18. VR application of 360-degree panoramic photo. 


\section{CONCLUSION AND OUTLOOK}

In this study, at first the inner and outer part of the mosque, which is the central element of the Complex, was modelled and VR application was prepared. The study will be expanded by adding interior models of the other structures of the Complex.

3-D models and VR technologies, reflecting actual dimensions and materials of cultural properties, provides data to the Historical Building Information System, where analytical and historical information can also be added. This can be used to make the maintenance sustainable with real-time data support. This study has been presented as an experience for similar studies protecting cultural properties. At the same time a working system and an improvable example are provided for building communities similar to the Suleymaniye Complex, which is included in the list of world heritage sites.

This study helps to increase the recognition of a cultural entity in the virtual environment on its own and it can also be used as a 3D survey. With this model, it will be possible to produce Historical Building Information Model which is an emerging approach that is being used in the Management of Cultural Properties. BIM technology, which is defined as a set of interrelated policies, processes and technologies that produces a systematic approach to managing critical information in a digital model, can be used as an integrated and effective method of managing the conservation process. The Heritage BIM system is a management system that integrates the historical knowledge of the architectural heritage and other information connected to the 3D model (Dore and Murphy, 2012).

Since 2000, the UNESCO World Heritage Committee has introduced the requirement to prepare a Management Plan for the effective protection and management of World Heritage Sites due to concerns and factors threatening the World Heritage Sites such as legal regulations, conservation approaches and plans, lack of coordination between the responsible institutions (UNESCO, 2017, URL02). The 3-D Model originated in this study will contribute to the monitoring process indicated in the proposed Management Plan for the Suleymaniye Complex.

3D VR application generated for the Suleymaniye Complex; HBIM application, 2D drawings and analyses that will be brought out as following steps based on the presented 3D Model; will give direction to the new studies as an output of this work. The VR application provides an important data for approaches such as virtual tour creation, access for disabled, and remote access. It is also an important data for digital simulation in risk management, empowerment, functionalization and similar scopes.

\section{REFERENCES}

Dore, C., Murphy, M., 2012. Integration of HBIM and 3D GIS for Digital Heritage Modelling, Digital Documentation, 22-23 October, 2012 Edinburgh, Scotland.

Dursun, S., Sagir, D., Büyüksalih, G., Buhur, S., Kersten, T., Jacobsen, K., 2008. 3D City Modelling of Istanbul Historic Peninsula by Combination of Aerial Images and Terrestrial Laser Scanning Data. 4th EARSel Workshop on Remote Sensing for Developing Countries/GISDECO 8, Istanbul, Turkey, June 4-7, 2008.
Kan, T. 2014. "İstanbul Suleymaniye Külliyesi Örneğinde Külliyeler için Bir Yönetim Modeli Yaklaşımı, Yayınlanmamış doktora tezi, Mimar Sinan Güzel Sanatlar Üniversitesi, Istanbul, pp.358.

Kan, T., Büyüksalih, G., Kaya, Başkaraca, A. P., 2017. The Importance of Digital Methods In Preservation of Cultural Heritage The Example of Zırnık1 Mansion. The International Archives of the Photogrammetry, Remote Sensing and Spatial Information Sciences, XLII-5/W1, GEOMATICS \& RESTORATION - Conservation of Cultural Heritage in the Digital Era, 22-24 May 2017, Florence, Italy, G. Tucci and V. Bonora (eds.), pp. 175-186.

Kersten, T., Büyüksalih, G., Baz, I., Jacobsen, K., 2009. Documentation of Istanbul Historic Peninsula by Kinematic Terrestrial Laser Scanning. The Photogrammetric Record, 24(126): 122-138.

Kersten, T., Büyüksalih, G., Tschirschwitz, F., Kan, T., Deggim, S., Kaya, Y., Baskaraca, A. P., 2017. The Selimiye Mosque of Edirne, Turkey - An Immersive and Interactive Virtual Reality Experience using HTC Vive. The International Archives of the Photogrammetry, Remote Sensing and Spatial Information Sciences, XLII-5/WI, GEOMATICS \& RESTORATION - Conservation of Cultural Heritage in the Digital Era, 22-24 May 2017, Florence, Italy, G. Tucci and V. Bonora (eds.), pp. 403-409.

Tschirschwitz, F., Büyüksalih, G., Kersten, T. P., Kan, T., Enc, G., Baskaraca, A.P., 2019. Virtualising an Ottoman Fortress Laser Scanning and 3D Modelling for the development of an Interactive, Immersive Virtual Reality Application. The International Archives of the Photogrammetry, Remote Sensing and Spatial Information Sciences, XLII-2-W9, 8th International Workshop 3D-ARCH 3D Virtual Reconstruction and Visualization of Complex Architectures, 6 - 8 February 2019, Bergamo, Italy, A. Cardaci, F. Fassi, and F. Remondino (eds.), pp. 723-729.

Ulusoy Binan, D., 2018. Tarihi ve Mimari Kültürel Miras Alanlarının Sürdürülebilir Korunmast, Şehir\&Toplum, Volume: 9, pp.23-32.

UNESCO, 2017. Historic Areas of Istanbul. URL01 https://whc.unesco.org/en/list/356 (6 Mart 2019).

UNESCO, 2017. The Operational Guidelines for the Implementation of the World Heritage Convention. URL02 https://whc.unesco.org/en/guidelines/ (6 Mart 2019). 